DOI: $10.7242 / 2658-705 X / 2019.3 .11$

УДК 328.3

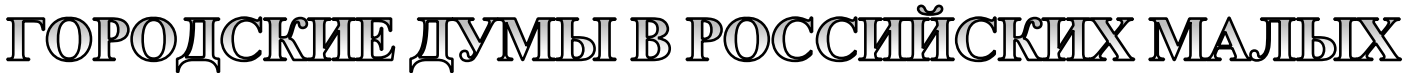

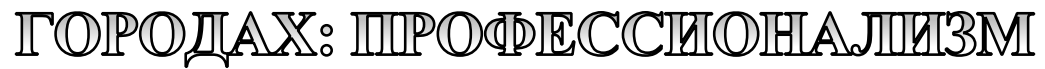

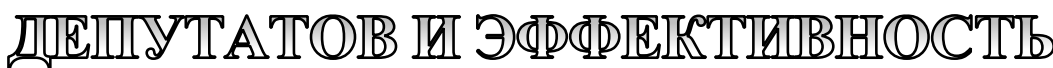 IDUPERCTA
}

Т.Б. Витковская, Пермский федеральный исследовательский центр УрО РАН

Статья посвящена проблеме профессионализма депутатов, работающих в составе представительных органов публичной власти в российских малых городах. Рассмотрены обязанности депутатов как «народных избранников» и представителей публичной власти. Выделены основные задачи, которые стоят перед депутатским корпусом, а также знания и умения, которые необходимы депутату для исполнения его обязанностей. Указаны основные проблемы, к которым может привести низкий уровень компетентности депутатов. Сделаны выводы о влиянии образования и профессионального опыта на эффрективность депутатской деятельности. Рассмотрена ситуация корпоративного представительства, когда избранные депутаты не мотивированы на работу в составе органа власти. Статья подготовлена на основе анализа материалов по ряду малых городов двух уральских регионов Свердловской области и Пермского края.

Ключевье слова: законодательная власть, представительная власть, местное самоуправления, муниципальное управление, депутатский корпус.

Введение. Эмпирическая база

Источниками статистического материала стали данные официальной электоральной статистики [5], которые содержат информацию о составе кандидатского пула и составе действующего депутатского корпуca, на основе которых можно сделать выводы об уровне образования депутатов и распределении их по профессиям. Сделанные выводы о составе представительных органов опираются на статистику по 25 малым городам Свердловской области и Пермского края. Города относятся к одной категории по численности населения (от 10 тыс. до 50 тыс. человек) и имеют небольшой разброс по численности депутатов представительных органов (от 15 до 25 человек).

Источниками эмпирического материала стали также интервью с представителями публичной власти в двух малых городах Свердловской области и одном малом городе в Пермском крае ${ }^{1}$. Представительные органы местного самоуправления в этих городах формируются по единой схеме: путем избрания определенного уставом числа депутатов на муниципальных выборах горожанами. Респондентами выступили главы администра-

\footnotetext{
* Работа выполнена в рамках государственного задания; номер государственной регистрации темы № AAAA-A19-119032590065-5.

${ }^{1}$ Города не называются, потому что некоторые интервью взяты на условии анонимности респондентов. 
ций, председатели и депутаты, бывшие депутаты представительных органов МСУ и руководители бюджетных учреждений. Проведенные глубинные интервью включали вопросы о деятельности городского представительного органа, эффективности его работы как института публичной власти и представительного института, сложностях и вызовах депутатской работы, профессионализме и компетенциях депутатов и т.д.

\section{Депутатская деятельность: задачи, вызовы и профессионализм}

Единого, общепринятого критерия для определения уровня профессионализма депутата не существует, поскольку в Российской Федерации депутат - это, в строгом смысле слова, не профессия, и депутатская деятельность - не профессиональная деятельность. Это верно и для депутатов, избираемых на субрегиональном уровне, - муниципальных депутатов. Избирательное право в России не содержит требований к уровню профессиональных правовых или иных знаний кандидатов в муниципальные депутаты.

Профессионализм депутата определяется тем, насколько успешно он справляется с задачами, которые ставит перед ним присутствие в представительном органе местного самоуправления.

Как показывает практика, одной из самых главных (и самых сложных) задач для депутата становится работа с муниципальным бюджетом. Председатель представительного органа говорит об этом: «Люди, приходя впервые в Думу, идут такими романтиками. Как правило, первый «удар об стену» - это формирование бюджета, когда есть очень четкие рам$\kappa и$, заданные извне, преодолеть которые невозможно» [1]. Актуальность этой задачи отражает значимость вопросов, связанных с местным бюджетом, в повестке муниципалитетов. В соответствии с законодательством, утверждение местного бюджета и отчет об его исполнении находятся в исключительной компетенции представительного органа муниципального обра- зования [8]. Это направление работы является одним из приоритетных для городских Дум, и вопросам муниципального бюджета уделяется значимая часть времени заседаний депутатских собраний.

В соответствии с законом об организации МСУ, к ведению представительного органа местного самоуправления относятся установление, изменение и отмена местных налогов и сборов, а также определение порядка распоряжения имуществом, находящимся в муниципальной собственности [8]. Это вовлекает депутатов в сложную для них работу по обеспечению наполняемости муниципального бюджета.

Компетентность депутата в вопросах, связанных с бюджетом, обеспечивает качественное профильное образование: минимальные необходимые знания дают все экономические специальности, большой объем знаний и умений обеспечивают дисциплины специальности «государственное и муниципальное управление» [4, с. 77]. Конечно, далеко не все депутаты, избранные на уровне муниципальных образований, имеют такое образование. Для многих из тех, кому полученное образование не может помочь в депутатской работе, источником необходимых навыков и знаний становится профессиональный опыт.

Руководители местных бюджетных учреждений, то есть учреждений, деятельность которых финансируется по большей части из бюджета [7], имеют представление о муниципальном бюджете, по крайней мере, в части его расходования и распределения бюджетных средств между основными получателями. Это директора школ и дошкольных учреждений, главные врачи больниц, директора библиотек и домов культуры, заведующие спортивными объектами и т.д.

Председатель городской Думы, в действующем созыве которой работают директора всех городских школ, сама - директор школы, рассказывает об их компетенциях: «Нам не надо объяснять очень многие процессы. Мы их знаем по себе. Формирование бюджета школь - это 
формирование бюджета города, в миниатюре. Проблемы школь - это проблемbl города, в миниатюре. То есть нам очень многого объяснять не надо, в этом отношении городским властям, я полагаю, с нами работать комфортнее» [2].

Необходимыми для работы в представительном органе компетенциями обладают депутаты, ранее занимавшие должности в муниципальной администрации: они хорошо знакомы с местным бюджетным процессом, системой организации городской власти, управленческим процессом. Представитель городской Думы объясняет, что есть необходимые депутатам знания: «Myниципальное управление - оно рамочное. Очень много точек. Один из таких регуляторов - это 44-й закон (Закон о контрактной системе в сфере закупок для муниципальных нужд - Т.В.) [9]» [1]. Представитель администрации поясняет, как работают депутаты, пришедшие из исполнительной власти: «Депутат уже поработавший - он действительно имеет опыт, опьт правильного балансирования между тем, что хочется народу, и тем, что необходимо. Поэтому ... уже более взвешенно подходит, более раџионально, из множества мероприятий, которые надо сделать, выбирается самое оптимальное» [3].

Безусловно, успешным как депутат будет и бывший глава города или глава администрации, если он решит продолжить политическую карьеру, избравшись в городскую Думу. Доля пришедших в представительную власть из исполнительной власти невелика, но даже один бывший глава или администратор может повысить профессиональный уровень депутатского собрания.

Депутаты участвуют в принятии решений, определяющих экономическую, налоговую, инфраструктурную политику муниципалитета. В исключительной компетенции представительного органа находится утверждение стратегии социально-экономического развития муниципального образования [8]. Вместе с тем депутаты постоянно вовлечены в текущую работу по решению многочисленных вопросов эконо- мического характера, по поддержанию инфраструктуры и городского хозяйства.

Экономическое образование, вне зависимости от специализации, может обеспечить необходимые каждому депутату знания о разных сторонах экономической жизни российского города, о рыночной среде в целом. Однако немногие муниципальные депутаты получили образование такого профиля.

Источником необходимых знаний для многих «народных избранников» становится не профессиональная подготовка, а профессиональный опыт: собственный опыт ведения бизнеса или работа по найму в сфере торговли, предоставления услуг или управления производством, на соответствующих должностях (от экономиста до бухгалтера).

Профессиональный опыт бизнесменов не только является ценным источником необходимой им в депутатской работе информации, но и формирует, в определенной степени, их стиль мышления и подход к решению проблем. Многие респонденты - представители органов местного самоуправления, говорят о разнице в «психологии» бизнесменов и бюджетников. Председатель городской Думы, руководитель образовательного учреждения, сравнивает: «Во-первых, у них склад ума другой, склад мышления другой. Наша работа - муниципальная, $\mathrm{Mbl}$ - сочиально зашчищенные слои населения. Почему мы сочиально зашищенные? У нас гарантия по зарплате, гарантия по больничному, гарантия по отпуску, гарантия по пенсии, у нас очень много гарантий. Находясь в этом гарантированном обществе, мы, может быть, не видим какие-то креативные пути мылиления. А предприниматель? Ему волей-неволей приходится крутиться-вертеться. Он что-то может подсказать. У нас был ..... директор птицефабрики, его можно назвать самым настоящим бизнесменом. Он очень грамотно давал пути развития. Как может развиваться город? Он показывал, как он может развиваться. Для меня это было очень большим подспорьем» [2]. 
Депутаты как работающие в представительном органе местного самоуправления вовлечены в нормотворческую деятельность. Эта роль не требует от них специализированных знаний: знаний о юридической технике и законотворческом процесce, - но эти знания могут помочь депутату работать эффективно. Например, глава администрации небольшого города так начинает разговор о работе с депутатами: «B нaстоящее время мы сталкиваемся со многими трудностями, и в первую очередь, наверно, - со знанием законодательства» [3].

Образование по юридической специальности, однако, получила малая часть местных депутатов - депутатов с таким образованием нет в большинстве городских Дум. Как правило, юридическое образование задает направление вектора карьеры и не предполагает уход на выборную позицию на муниципальном уровне.

Образование по специальности «государственное и муниципальное управление» может дать депутату необходимые ориентиры. Однако знания, важные для понимания нормотворческого процесса и умения, нужные для реального влияния на него, депутатам дает прежде всего опыт. В данном случае речь идет не о профессиональном опыте, а об опыте именно депутатской работы.

Депутат, работающий в представительном органе несколько лет, является более компетентным как законодатель, чем депутат, работающий первый год. Депутат - «ветеран», который успешно избирался в городскую Думу не один раз, становится более подготовленным и компетентным, чем его коллеги без такого опыта. Председатель городской Думы так формулирует мнение, с которым согласны многие депутаты: «Я вообще сторонник того, что выбираться на один сезон смысла нет - продвижения не будет» [1].

Разделение депутатов на комиссии и комитеты в соответствии с их профессией, опытом или интересами помогает им работать более эффективно, поскольку позволяет депутатам сосредоточиться на вопросах, в которых они более компетентны.
Как правило, руководители муниципальных бюджетных учреждений состоят в комитете по бюджету и налогам, а бизнесмены работают в комитетах по экономической политике, или градостроительству, или городскому хозяйству.

\section{Работа депутата: вовлеченность, мотивация и эффективность}

Спорным остается вопрос о целесообразности работы депутатов в представительном органе на освобожденной основе (без совмещения с другой профессиональной деятельностью, за вознаграждение). В настоящее время большинство депутатов городских Дум в выбранных для исследования регионах работают на неосвобожденной основе.

Работа на освобожденной основе позволяет членам депутатского корпуса сосредоточиться на выполнении депутатских обязанностей. Это помогает быстрее накопить необходимый опыт нормотворческой работы и работы с бюджетом. Кроме того, располагая временем более свободно, депутаты могут больше времени уделять деятельности вне заседаний, например, подготовительной работе с документами, работе в рамках комиссий и рабочих групп. Таким образом эффективность работы депутата, если понимать ее как внесение существенного вклада в нормотворческий процесс и активное участие в работе представительного органа, будет расти.

В то же время депутат является в первую очередь представителем: и всего населения муниципального образования (поскольку именно через него жители реализуют свое право на осуществление власти на местном уровне) [8], и своего избирательного округа, и, в определенном смысле, своей социальной группы или профессиональной когорты. Так, депутат - директор школы, представляет в депутатском собрании сферу городского образования, депутат - главный врач больницы - сферу городского здравоохранения, и каждый из них - систему социально значимых муниципальных бюджетных учреждений. Отрыв от основного 
места работы может сделать депутата в большей степени представителем власти, чем представителем своей сферы или группы. Это, безусловно, осложняет выполнение депутатом предписанной ему представительской функции.

Успешность работы «народного избранника» в депутатском собрании зависит и от его личных качеств: обучаемости, целеустремленности, работоспособности, а также коммуникационных навыков и психологических особенностей.

Профессионализм депутата тесно связан с его мотивацией. Если депутат слабо мотивирован на работу в составе органа управления: остается пассивен, сосредоточен только на основной трудовой деятельности, - его вклад в работу представительного органа МСУ будет малым, эффективность его работы как депутата - низкой.

Как правило, представители бюджетных учреждений социального профиля часто проявляют интерес к работе представительных органов, выдвигают свои кандидатуры, получают искомую поддержку горожан на выборах и остаются достаточно активны в составе депутатского собрания. Местные бизнесмены также, если избираются в состав органа публичной власти, за отдельными исключениями, демонстрируют инициативность и активность, хотя они не всегда направлены на нормотворческий процесс и не все направления деятельности представительного органа им одинаково интересны, некоторые - остаются вне фокуса их внимания.

Мотивированы на работу в представительном органе и депутаты, которые не ведут другой, профессиональной деятельности, например, пенсионеры или временно безработные. Работа в депутатском собрании зачастую становится для них способом социализации или самореализации.

Слабо мотивированы на депутатскую работу представители особой категории рядовые работники крупных предприятий, которые имеют мандаты. Их присутствие в городских Думах и отсутствие у них мотивации к работе объясняются формой политического представительст- ва крупных предприятий, получившей широкое распространение на городском уровне. Многие крупные предприятия формируют в представительных органах местного самоуправления территорий, где расположены их производства или другие крупные объекты, депутатские группы, которые защищают их интересы. Подобные корпоративные депутатские группы позволяют контролировать нормотворческий процесс, обеспечивая принятие решений, необходимых руководству или собственникам предприятий, и блокировку решений, невыгодных им.

Для того, чтобы иметь возможность контролировать результаты депутатских голосований через «своих» депутатов, предприятия должны иметь численное превосходство в городских Думах - их представители должны составлять не менее половины депутатского корпуса. По этой причине корпоративные депутатские группы, как правило, составлены рядовыми работниками предприятий, большинство из которых - «синие воротнички», представители рабочих профессий.

Для этих депутатов роль, которую они исполняют в системе органов самоуправления, остается навязанной. Они, за отдельными исключениями, воспринимают депутатские обязанности как помеху их основной трудовой деятельности. Их отличают от большинства коллег по депутатскому корпусу пассивность, безынициативность и слабая мотивация к работе.

Кроме того, их трудовой опыт не дал им необходимых для депутатской работы знаний или навыков, как и их образование, как правило, среднее специальное, по рабочей специальности. Компетентность депутатов «от завода» вызывает обоснованные сомнения, даже с учетом в целом невысокого образовательного уровня местного депутатского корпуса и малого числа депутатов с соответствующим исполняемой роли образованием.

\section{Заключение}

Знания о системе государственного и муниципального управления, а также 
юридические и экономические знания являются профильными в депутатской деятельности. Однако депутаты, получившиеся образование по этим специальностям, не составляют большинства в депутатском корпусе малых городов Свердловской области и Пермского края. Тем не менее это не причина для заключения о низком профессиональном уровне депутатских собраний данных территорий. В малых городах проблемы с образовательным уровнем и специализацией компенсирует личный профессиональный опыт депутатов - предпринимателей, администраторов и руководителей бюджетных организаций, которые заполняют городские Думы.

Профессионала в городской Думе формирует также опыт политической социализации. Первым этапом становится избирательная кампания, которая дает опыт общения с избирателями, представление об актуальных проблемах территории и требует выработать конкретные инициативы по их разрешению [6, с. 89]. Далее, в ходе работы в городской Думе, депутат приобретает и накапливает уникальный опыт: на заседаниях, в профильных комиссиях и комитетах, в ходе самостоятельной работы и совместной работы с представителями муниципальной администрации.

Большинство муниципальных депутатов не являются профессиональными политиками, оставаясь прежде всего профессионалами в сфере и на месте своей основной занятости. Вместе с тем понимание ими смысла своей деятельности если не как призвания и профессии, то как работы, значимой для локального сообщества или своей референтной группы (аффилиации могут быть самыми разными, важно именно осознание представительской функции), помогает им выполнять эту работу более ответственно и профессионально.

\section{Библиографический список}

1. Интервью №1. Взято Т.Б.Витковской. Не опубликовано. Архив автора.

2. Интервью №2. Взято Т.Б.Витковской. Не опубликовано. Архив автора.

3. Интервью №3. Взято Т.Б.Витковской. Не опубликовано. Архив автора.

4. Мохов В.П. Проблемы подготовки кадров для системы государственного и муниципального управления в современных условиях // Высшее профессиональное образование, бизнес, власть: опыт и перспективы взаимодействия в подготовке управленческих кадров, ориентированных на инновации: сб. статей. - Пермь: ЗУИЭиП, 2009. - С. 76-80.

5. Официальный сайт Центральной избирательной комиссии Российской Федерации. Информация о выборах и референдумах [Электронный ресурс] - URL: http:/www.vybory.izbirkom.ru/ (дата обращения: 12.06.2019).

6. Подвинщеев О.Б., Витковская Т.Б. Муниципальная политическая элита Пермского края: уровень образовательной подготовки и возможности его совершенствования // Высшее профессиональное образование, бизнес, власть: опыт и перспективы взаимодействия в подготовке управленческих кадров, ориентированных на инновации: сб. статей. - Пермь: ЗУИЭиП, 2009. - С. 89-93.

7. Федеральный закон от 12 января 1996 г. № 7-Ф3 «О некоммерческих организациях» - URL: http://www.consultant.ru/document/cons_doc_LAW_8824/(дата обращения: 12.06.2019).

8. Федеральный закон от 6 октября 2003 г. № 131-Ф3 (ред. от 01.05.2019, с изм. от 03.07.2019) «Об общих принципах организации местного самоуправления в Российской Федерации» - URL: http://www.consultant.ru/document/cons_doc_LAW_44571/(дата обращения: 11.06.2019).

9. Федеральный закон от 5 апреля 2013 г. № 44-Ф3 «О контрактной системе в сфере закупок товаров, работ, услуг для обеспечения государственных и муниципальных нужд» - URL: http://www.consultant.ru/document/cons_doc_LAW_144624/(дата обращения: 13.06.2019). 


\title{
LOCAL LEGISLATURES IN SMALL RUSSIAN CITIES: \\ PROFESSIONALISM OF DEPUTIES AND EFFICIENCY OF REPRESENTATIVE BODY OF LOCAL GOVERNMENT
}

\author{
T.B. Vitkovskaya \\ Perm Federal Research Center UB RAS
}

The article attempts to analyze the issue of professionalism of deputies working within representative bodies of local government in small Russian cities. The duties of deputies as elected officials and representatives of public authority system are considered. The main tasks for deputies are highlighted, as well as knowledge and skills that a deputy should fulfill. The main problems to which low competency of deputies can lead are indicated. Conclusions concerning the impact of education and professional experience on the effectiveness of parliamentary activity are made. The situation of corporate representation, when elected deputies are not motivated to work as a part of public urban authority system, is described. The article is based on the analysis of materials from a number of small cities in Sverdlovskaya oblast and Perm region.

Keywords: the legislature, local government, representative body of local government.

\section{Сведения об авторе}

Витковская Татьяна Борисовна, кандидат политических наук, научный сотрудник отдела по исследованию политических институтов и процессов, Пермский федеральный исследовательский центр УрО РАН (ПФИЦ УрО РАН), 614990, г. Пермь, ул. Ленина, 13А; e-mail: vit.tatiana@gmail.com 